\title{
Morphological Investigation of Calcium Carbonate during Ammonification-Carbonization Process of Low Concentration Calcium Solution
}

\author{
Huaigang Cheng, Xiaoxi Zhang, and Huiping Song \\ Institute of Resources and Environment Engineering, State Environment Protection Key Laboratory of Efficient Utilization of \\ Coal Waste Resources, Shanxi University, Taiyuan 030006, China \\ Correspondence should be addressed to Huiping Song; songhp@sxu.edu.cn
}

Received 15 July 2014; Accepted 5 August 2014; Published 2 September 2014

Academic Editor: Xinqing Chen

Copyright (C) 2014 Huaigang Cheng et al. This is an open access article distributed under the Creative Commons Attribution License, which permits unrestricted use, distribution, and reproduction in any medium, provided the original work is properly cited.

Ultrafine calcium carbonate is a widely used cheap additive. The research is conducted in low degree supersaturation solution in order to study the polymorphic phases' change and its factors of the calcium carbonate precipitate in the ammonificationcarbonization process of the solution with calcium. Fine particles of calcium carbonate are made in the solution containing $0.015 \mathrm{~mol} / \mathrm{L}$ of $\mathrm{Ca}^{2+}$. Over $98 \%$ of the calcium carbonate precipitate without ammonification resembles the morphology of calcite, while the introduction of ammonia can benefit the formation of vaterite. It was inferred that the main cause should be serious partial oversaturation or steric effects. Ammonia also helps to form the twin spherical calcium carbonate. However, particles formed in the process of ammonification-carbonization in solution with low concentration degree of calcium are not even with a scale of the particle diameter from 5 to $12 \mu \mathrm{m}$. Inorganic salts, alcohol, or organic acid salts have significant controlling effect on the particle diameter of calcium carbonate and can help to decrease the particle diameter to about $3 \mu \mathrm{m}$. Anionic surfactants can prevent the conglobation of calcium carbonate particles and shrink its diameter to $500 \mathrm{~nm}-1 \mu \mathrm{m}$.

\section{Introduction}

Ultrafine calcium carbonate of nano- and submicron size is widely used as cheap additive in manufacturing plastic, rubber, varnish, ink, paper, paint, medicine, and other fields $[1,2]$. Calcium carbonate and inorganic oxide have good affinity; therefore, it can be used as the model material $[3,4]$ to make inorganic hollow microsphere such as $\mathrm{SiO}_{2}$ and $\mathrm{TiO}_{2}$. The reason why calcium carbonate can be so widely used is that it has a unique crystal structure and particle size.

Calcium carbonate has three kinds of crystal polymorphs [5], namely, spherical vaterite, aragonite in the shape of a needle, and rhomboidal calcite. The energy level decreases according to this order, while the stability increases. Calcium carbonate of calcite type can stay stable at room temperature, while those of vaterite and aragonite type with metastability are easier to be transformed into the calcite type. Spherical calcium carbonate is commonly used for its smoothness and fluidity. Usually, it is a porous structure and resembles the clustering with microcrystal of nanosize $(25-35 \mathrm{~nm})$. Large amounts of expensive biological macromolecules, dendronized polymers, or compound additives as crystalline controller are used to form spherical calcium carbonate, and less cheap acid, alkali, and salt are used to control the crystal shape.

There are many ways to compose calcium carbonate including carbonization, precipitate method, and high gravity method. Carbonization refers to the method of adding $\mathrm{CO}_{2}$ gas to suspension with $\mathrm{Ca}^{2+}$ and adding morph regulator to control the growing rate of each face of the crystal to achieve morphology control. Precipitate method is to mix the solution of $\mathrm{Ca}^{2+}$ and $\mathrm{CO}_{3}{ }^{2-}$ to make calcium carbonate particles. High gravity method is to create the condition for the intensive mixing of liquid and raise the reaction rate of calcium carbonate with centrifugal force. Ultrafine calcium carbonate is mainly synthesized in liquid. Controlling the operation conditions, like temperature, $\mathrm{pH}$, and 
supersaturation, or adding crystalline regulator, it can influence nucleation, formation, and the final polymorph of calcium carbonate [6]. Commonly used crystalline regulators include chelating agent [7], organic compound [8, 9], inorganic salt, minerals, organic acid [10], alcohol, amino acid [11], and chitosan. The morphology of calcium carbonate can also be induced by biological factors [12]. From the dynamics perspective, mixed solution can help to form the crystal of metastability, for example, the mixture of alcohol and water. With ammonia, hexagonal calcium carbonate crystal can be formed by the self-assembly of vaterite nanoparticles. While in the reaction of $\mathrm{CO}_{2}$ gas and $\mathrm{CaCl}_{2}$ solution, ammonia can function to shape the $\mathrm{CaCO}_{3}$ into spherical vaterite of metastability [13]. In addition, the spherical $\mathrm{CaCO}_{3}$ after thermal decomposition becomes spherical $\mathrm{CaO}$ which can be used as catalyst in biodiesel or to manufacture the organic light-emitting diode. Magnesium also plays an important role in the precipitation of calcium carbonate. When the $\mathrm{Mg}^{2+}$ concentration degree is low, calcite is formed; when it is high, aragonite is formed.

Making ultrafine calcium carbonate, mix solution with $\mathrm{Ca}^{2+}$ and solution with $\mathrm{CO}_{3}{ }^{2-}$ or add organic substance to regulate the mass transfer of $\mathrm{Ca}^{2+}$ and $\mathrm{CO}_{3}{ }^{2-}$ to control nucleation and formation of crystal. What is more, $\mathrm{CO}_{2}$ gas can be added to $\mathrm{Ca}(\mathrm{OH})_{2}$ solution [14]. The method of the reaction of $\mathrm{Ca}(\mathrm{OH})_{2}$ solution and $\mathrm{CO}_{2}$ gas [15] is the major way for industrial ultrafine calcium carbonate making considering the production cost. However, in this method, $\mathrm{Ca}(\mathrm{OH})_{2}$ solution can also be replaced by other solutions with $\mathrm{Ca}^{2+}$, such as $\mathrm{CaCl}_{2}$ solution. The solution should be changed to alkaline in order to make the reaction with $\mathrm{CO}_{2}$ happen faster, and the process of alkalinization is usually achieved by using ammonia solution. Also, the method of adding ammonia and $\mathrm{CO}_{2}$ gas to gypsum serum to make ammonia sulfate is to recycle the gypsum to solid wastes and has produced calcium carbonate as well. The common method of making calcium carbonate in existing findings is basically using solution with high concentration of $\mathrm{Ca}^{2+}$ as source of calcium, through which enough calcium carbonate can be obtained. However, solution with low concentration of $\mathrm{Ca}^{2+}$ is also worth being studied $[16,17]$. The supersaturation degree will remain at a low level. Theoretically, in the system with low degree of supersaturation, the control of the morphology of calcium carbonate particles will be easier. In the process of formation and precipitation of crystal, the solution becomes supersaturated and the crystal nucleus is formed with the clashes of ions. Then the ions that constructed the crystal in the solution diffuse and precipitate on the surface of crystal nucleus, which is called the crystal nucleus growth. Crystal nuclei form crystal particles gradually, and particles concentrate and form crystal with orientation arrangement. If the supersaturation degree is too high, it is easy to form amorphous precipitate. With a low supersaturation degree, the growth velocity of crystal is slow, and the surface of crystal is well formed. When the supersaturation degree is too high, the reaction of $\mathrm{Ca}^{2+}$ and $\mathrm{CO}_{3}{ }^{2-}$ will be too quick to control the crystal morphology. Thus, the control of reaction speed is usually achieved by controlling the concentration of participating substances [18, 19]; for example, in the formation process of biological mineralization (such as the formation of shell), semipermeable membrane is used to control the release of $\mathrm{Ca}^{2+}$ or $\mathrm{CO}_{3}{ }^{2-}$. It will function to control the crystal morphology of calcium carbonate.

The focus of this paper is to analyze the morphology of the calcium carbonate precipitate of low concentration degree and the way to control its morphology to infer the formation mechanism of calcium carbonate materials. It is of great importance to research on making nano- and submicron calcium carbonate materials in solutions with $\mathrm{Ca}^{2+}$, such as $\mathrm{CaCl}_{2}$. It can also explain how solutions with low concentration of $\mathrm{Ca}^{2+}$, such as calcium sulfate, can form the calcium carbonate materials with unique morphology.

\section{Experimental Details}

Calcium carbonate precipitate is made by adding $\mathrm{CO}_{2}$ gas to solution with $\mathrm{Ca}^{2+}$. Calcium sulfate saturated solution with about $0.015 \mathrm{~mol} / \mathrm{L}$ of $\mathrm{Ca}^{2+}$ is used since it will be a proper concentration for the calcium carbonate precipitating. If we need a higher concentration of $\mathrm{Ca}^{2+}, \mathrm{CaCl}_{2}$ solution is used. Since calcium sulfate or $\mathrm{CaCl}_{2}$ solution is neutral, $\mathrm{Ca}^{2+}$ and $\mathrm{CO}_{2}$ will not react. Thus, ammonia liquid is added to the solution as follows:

$$
\mathrm{Ca}^{2+}+2 \mathrm{NH}_{3}+\mathrm{CO}_{2}+\mathrm{H}_{2} \mathrm{O}=2 \mathrm{NH}_{4}^{+}+\mathrm{CaCO}_{3}
$$

The reagents and additives used in this experiment include calcium sulfate, calcium chloride, sodium carbonate, sodium chloride, ammonia, alcohol, and sodium acetate, which are all analytical reagents (BOLT Tianjin Chemical Co., Ltd., China). A $\mathrm{CO}_{2}$ cylinder (99.5\% in purity) is used to provide carbon source. The anionic surfactant (Nafine Chemical Industry Group Co., Ltd., China) including sodium alkane sulfonate and poly(oxy-1,2-ethanediyl),asulfo-w-(dodecyloxy)-, sodium salt $(1: 1)$ which is usually used as a detergent is used to control the crystal morphology.

Scanning electron microscope (SEM, JEOL JSM-6701F, Japan) is applied to inspect the morphology of the formed calcium carbonate and X-ray powder diffraction (XRD, Bruker D2 Advance Phaser, Germany) to analyze its crystalline phase. When XRD is used to analyze the crystal morphology, lattice planes 104, 113, 202, 024, 116, 221, and 122 correspond to the diffraction peaks of crystal planes of the calcite, while $110,112,114$, and 300 correspond to the diffraction peaks of crystal plane of vaterite. According to the literature [20], the proportion of vaterite $\left(f_{v}\right)$ can be calculated as follows:

$$
f_{v}=\frac{\left(I_{110 v}+I_{112 v}+I_{114 v}\right)}{\left(I_{110 v}+I_{112 v}+I_{114 v}+I_{104 c}\right)},
$$

where $I$ is the intensity of diffraction peak, the subscript $v$ represents the vaterite, and $c$ represents calcite.

\section{Results and Discussion}

3.1. Influence of Ammonia on the Crystal Phase of Calcium Carbonate. To investigate the influence of ammonia on 


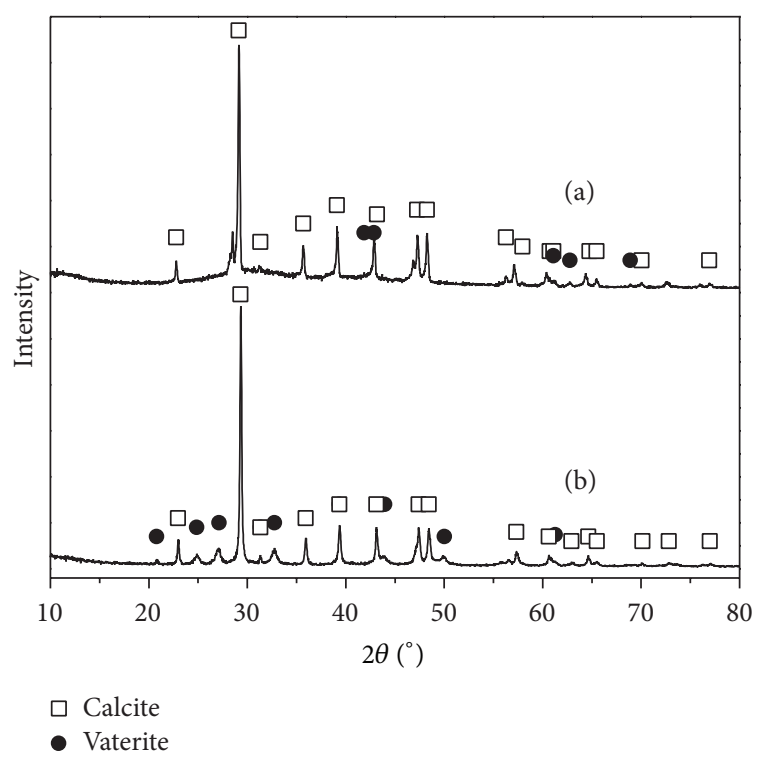

FIgURE 1: Crystal phase of calcium carbonate precipitate. (a) Solutions: $\mathrm{CaCl}_{2}, 0.18 \mathrm{~mol} / \mathrm{L} ; \mathrm{Na}_{2} \mathrm{CO}_{3}, 0.18 \mathrm{~mol} / \mathrm{L}$. (b) Solutions: $\mathrm{CaCl}_{2}$, $0.13 \mathrm{~mol} / \mathrm{L} ; \mathrm{NH}_{3}, 0.74 \mathrm{~mol} / \mathrm{L}$. $\mathrm{CO}_{2}$ gas: $60 \mathrm{ml} / \mathrm{min} \times 20 \mathrm{~min}$.

crystal polymorphs of calcium carbonate precipitate, the XRD spectra of calcium carbonate obtained in two reaction systems, one with ammonia and the other without, were compared, as shown in Figure 1. The calcium carbonate obtained by mixing calcium chloride and sodium carbonate solutions is shown in Figure 1(a). Figure 1(b) is the calcium carbonate obtained by mixing calcium sulfate solution with ammonia liquid and $\mathrm{CO}_{2}$ gas. The concentration degrees of $\mathrm{Ca}^{2+}$ of two experiments are similar.

Figure 1(a) shows that when ammonia is not added, calcite is the major crystal morphology of calcium carbonate precipitate, containing a little crystal morphology of vaterite. According to (2), the proportion of calcite is $98.52 \%$, while the remaining $1.48 \%$ is the vaterite, in terms of their total amount. When ammonia is added to the solution, the characteristic peak of vaterite is intensified, as shown in Figure 1(b). The precipitate at this time contains crystal morphology of both calcite and vaterite and a little aragonite. The calculation in (2) shows that the proportion of calcite reaches $87.83 \%$ of the total amount of calcite and vaterite, while the rest $12.17 \%$ is vaterite. It shows that adding ammonia functions to form vaterite.

When ammonia is used to form calcium carbonate precipitate, the $\mathrm{pH}$ is controlled between 8 and 11 [13], which is the interval to form spherical vaterite steadily. The reaction process includes $\mathrm{CO}_{2}$ dissolving in water, ammonia and water forming $\mathrm{NH}_{4}^{+}$, and $\mathrm{OH}^{-}, \mathrm{CO}_{2}$, and $\mathrm{OH}^{-}$forming $\mathrm{HCO}_{3}{ }^{-}$. Finally, $\mathrm{CO}_{3}{ }^{2-}$ is formed, and calcium carbonate is formed with $\mathrm{Ca}^{2+}$ and $\mathrm{CO}_{3}{ }^{2-}$. In this process, the speed controlling step is the formation of $\mathrm{HCO}_{3}{ }^{-}$. Supersaturation degree of calcium carbonate around the $\mathrm{CO}_{2}$ gas bubbles is very high, which provides condition to create the new solid particles. When degree of supersaturation is maintained at a relatively high value, new vaterite will form its nucleus around the
$\mathrm{CO}_{2}$ bubbles. The dense nucleation of vaterite prevents it from dissolving and renucleation and prevents the growth of more stable calcite crystal. High degree of supersaturation can benefit to form the metastable vaterite in the dynamics perspective and stop it from transforming into calcite. The supersaturation degree can be achieved with high $\mathrm{pH}$ since when $\mathrm{pH}$ is high, the speed of dissolving $\mathrm{CO}_{2}$ and forming $\mathrm{CO}_{3}{ }^{2-}$ is fast, which can be achieved by adding ammonia. Thus, when ammonia exists in solution, it is easy to form calcium carbonate precipitate with crystal morphology of vaterite.

3.2. Influence of Ammonia on the Morphology of Calcium Carbonate Precipitate. Figure 2 shows, under different operation, ammonia has impact on the morphology of calcium carbonate precipitate. Figure 2(a) indicates that when solutions with $\mathrm{Ca}^{2+}$ and $\mathrm{CO}_{3}{ }^{2-}$ are mixed, the calcium carbonate precipitate is cubic, which is the morphology of calcite. After ammonia is added, as shown in Figure 2(b), the precipitate embodies the rough spherical shape, ellipsoidal shape, and twin spherical shape. On the one hand, the reason can be that ammonia raised the supersaturation degree of calcium carbonate to form spherical calcium carbonate. On the other hand, the amount of $\mathrm{Ca}^{2+}$ and $\mathrm{CO}_{3}{ }^{2-}$ decreased as the reaction went on, and degree of supersaturation decreases, which makes spherical calcium carbonate tends to form more stable cube. Thus, the crystal manifests the topograph of calcite, and edges and corners become sharper. These two conditions affect each other. As a result, the calcium carbonate precipitate shows the rough spherical morphology. Meanwhile, it is assumed that calcium carbonate particles in the solution form cubic or spindle-shaped crystal nucleus. The crystal nuclei have high surface energy in the direction of edge and corner. With the steric effect of ammonia, partial $\mathrm{Ca}^{2+}$ and $\mathrm{CO}_{3}{ }^{2-}$ at the edge and corner direction concentrate and grow quickly, and partial degree of supersaturation is very high. Many small crystal particles formed in the process of nucleation. Particles formed twin spherical calcium carbonate by combining themselves to achieve the minimization of surface area.

Figures 2(c) and 2(d) show another growth type of crystal. It is in the system of $\mathrm{Ca}^{2+}$ solution and $\mathrm{CO}_{2}$ gas bubbles. Since $\mathrm{CO}_{2}$ gas is continuously added to the solution, the degree of supersaturation in the reaction will not be decreased and can be maintained at a certain level. When the amount of ammonia is small and cannot maintain the degree of supersaturation at the level of producing vaterite, the calcium carbonate includes cube and needle-cluster shape. When the amount of ammonia is big, most of the calcium carbonate precipitate is spherical, which shows that ammonia has influence on the topograph of calcium carbonate. It means that ammonia can help the calcium carbonate to precipitate in the morphology of vaterite. In most cases, it is well known that the calcium carbonate tends to form the stable cube shape. Therefore, the needle-cluster calcium carbonate may be assumed to be the transition morphology between the cubic and spherical shape under the effect of ammonia. 


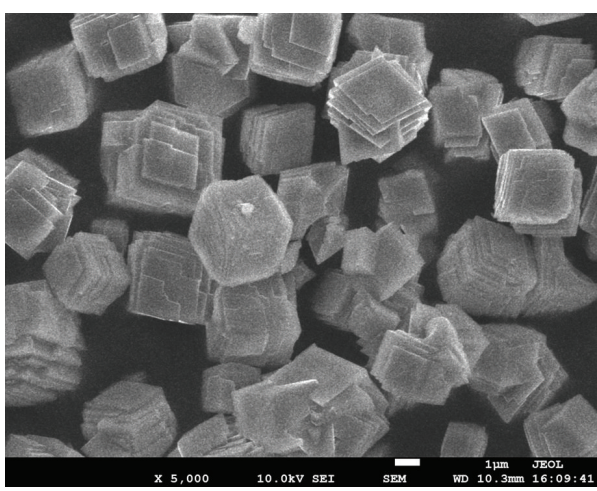

(a) Solutions: $\mathrm{CaCl}_{2}, 0.18 \mathrm{~mol} / \mathrm{L} ; \mathrm{Na}_{2} \mathrm{CO}_{3}, 0.18 \mathrm{~mol} / \mathrm{L}$

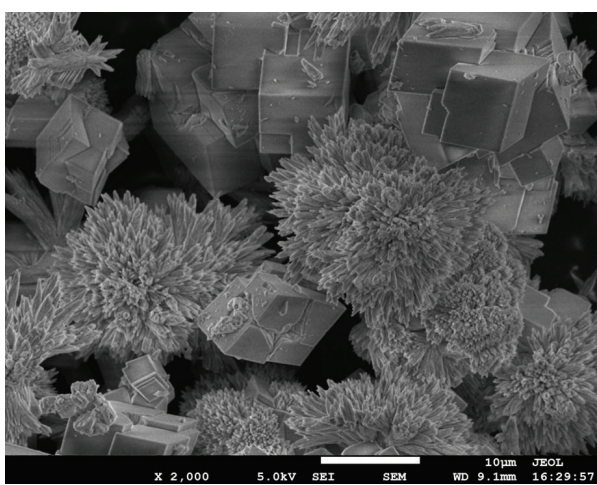

(c) Solutions: $\mathrm{NH}_{3}, 0.36 \mathrm{~mol} / \mathrm{L} ; \mathrm{CaSO}_{4}, 0.15 \mathrm{~mol} / \mathrm{L}$. $\mathrm{CO}_{2}$ gas: $60 \mathrm{~mL} / \mathrm{min} \times 20 \mathrm{~min}$

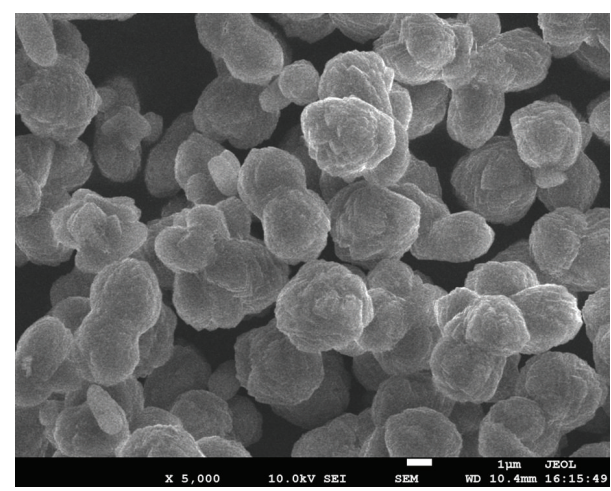

(b) Solutions: $\mathrm{CaCl}_{2}, 0.18 \mathrm{~mol} / \mathrm{L} ; \mathrm{Na}_{2} \mathrm{CO}_{3}, 0.18 \mathrm{~mol} / \mathrm{L}$; $\mathrm{NH}_{3}, 3.39 \mathrm{~mol} / \mathrm{L}$

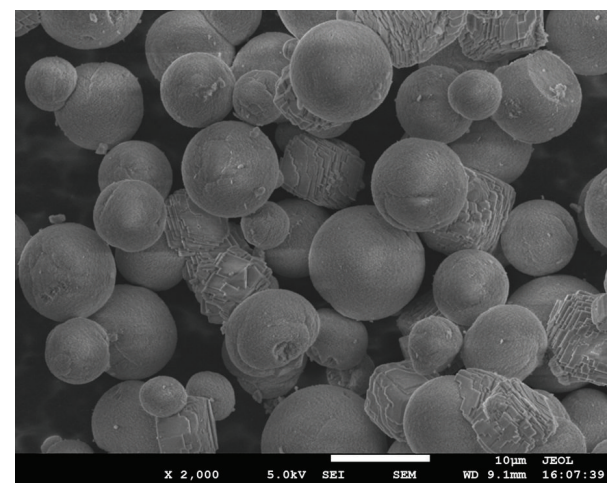

(d) Solutions: $\mathrm{NH}_{3}, 1.47 \mathrm{~mol} / \mathrm{L} ; \mathrm{CaSO}_{4}, 0.15 \mathrm{~mol} / \mathrm{L}$. $\mathrm{CO}_{2}$ gas: $60 \mathrm{~mL} / \mathrm{min} \times 20 \mathrm{~min}$

FIGURE 2: Morphology of calcium carbonate precipitate with and without ammonification.

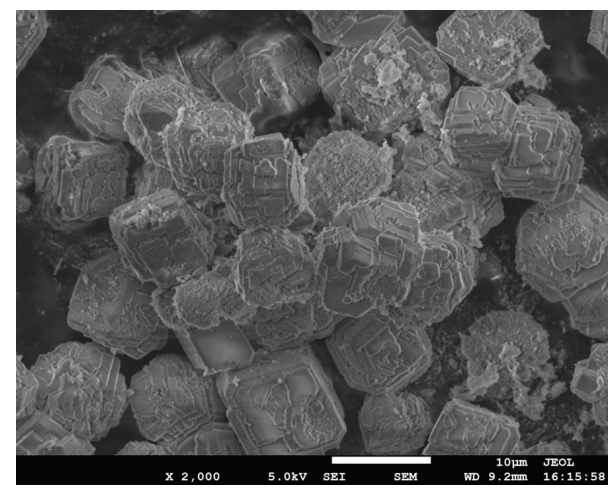

FIGURE 3: Morphology of calcium carbonate precipitate. Solutions: $\mathrm{CaSO}_{4}, 0.15 \mathrm{~mol} / \mathrm{L}$. $\mathrm{CO}_{2}$ gas: $55 \mathrm{~mL} / \mathrm{min} \times 20 \mathrm{~min}$. Final $\mathrm{pH}=10$.

Figure 3 shows the precipitate of calcium carbonate in another reaction system. Constantly adding $\mathrm{CO}_{2}$ in the saturated solution of calcium sulfate until $\mathrm{pH}$ decreases from 7 to 4.6 and adding ammonia liquid and controlling the $\mathrm{pH}$ of the solution at 10 , the precipitate of the calcium carbonate is shown in Figure 3. Before adding ammonia liquid, the $\mathrm{Ca}^{2+}, \mathrm{SO}_{4}{ }^{2-}$, and $\mathrm{H}_{2} \mathrm{CO}_{3}$ will not react. After adding ammonia, calcium carbonate precipitate and ammonia sulfate are formed instantly. The reason inferred is that the degree of supersaturation became high suddenly. Therefore, the crystal morphology is the spherical vaterite. However, without new supplementing $\mathrm{CO}_{2}$, the amount of $\mathrm{Ca}^{2+}$ and $\mathrm{H}_{2} \mathrm{CO}_{3}$ decreased as the reaction went on, and the degree of supersaturation is decreased as well. The shape of vaterite gradually transforms into calcite. Figure 3 shows the intermediate state of spherical crystal morphology transforming into cubic crystal morphology, and the comparison with Figure 2(a) explains that the effect of ammonia in the calcium carbonate crystal growing process is to accelerate the precipitate into spherical morphology.

The ultrasound usually has an influence on the precipitation of calcium carbonate [21]. Ultrasound can make the suspended particles dispersed and has a role in preventing the formation of large particles precipitated. Therefore, under the effect of ultrasound, the precipitate formed will be relatively small. With the interference of ultrasound, we can see clearer the effect of ammonia on shaping particle morphology of precipitate. Without ammonia, calcium carbonate precipitate with ultrasound shows the cubic and spindle-shaped morphology, like in Figure 4(a). Figure 4(b) indicates that when increasing the amount of ammonia, ammonia accelerates the transformation of cubic calcium carbonate particles into rough spherical morph and eggshaped morphology, as shown in Figure 4(a). Apparently, the surface is a bit sharp, which means the formation still 


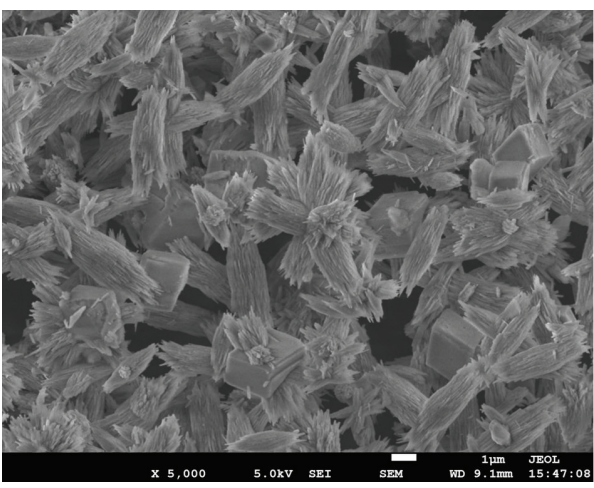

(a) Solutions: $\mathrm{NH}_{3}, 1.47 \mathrm{~mol} / \mathrm{L} ; \mathrm{CaSO}_{4}, 0.15 \mathrm{~mol} / \mathrm{L}$ $\mathrm{CO}_{2}$ gas: $1560 \mathrm{~mL} / \mathrm{min} \times 20 \mathrm{~min} . \mathrm{CO}_{2}(\mathrm{v} \%)=3.88 \%$

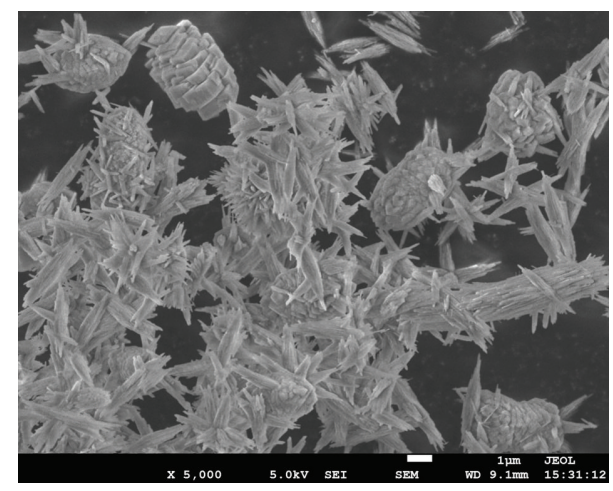

(b) Solutions: $\mathrm{NH}_{3}, 3.39 \mathrm{~mol} / \mathrm{L} ; \mathrm{CaSO}_{4}, 0.15 \mathrm{~mol} / \mathrm{L}$. $\mathrm{CO}_{2}$ gas: $1560 \mathrm{~mL} / \mathrm{min} \times 20 \mathrm{~min} . \mathrm{CO}_{2}(\mathrm{v} \%)=3.88 \%$

FIgURE 4: Morphology of calcium carbonate precipitate under ultrasound.

obeys the rule of forming calcite, while the look is more like a sphere. Ammonia can influence the morphology of calcium carbonate precipitate developing into sphere. Apart from increasing the degree of supersaturation, steric effect may be used to accelerate the spherical formation of calcium carbonate.

\subsection{Controlling the Morphology of Calcium Carbonate by} Electrolyte and Surfactant. With different types of electrolyte, ammonia can have different effects on calcium carbonate particles, as shown in Figures 5(a) and 5(b). When adding inorganic salt to increase the ion strength, morphology of calcium carbonate particles has two conspicuous changes. First, the diameter decreases from $5 \sim 12 \mu \mathrm{m}$ to $5 \mu \mathrm{m}$. Second, clustering of particles and twin spherical polymorph appear. Figures 5(c) and 5(d) show that, by adding alcohol and organic acid and salt, the diameter of calcium carbonate particles decreases to about $3 \mu \mathrm{m}$ and the clustering effect becomes more conspicuous. In Figure 5(e), the anionic surfactant can decrease the diameter of calcium carbonate particles to $500 \mathrm{~nm}-1 \mu \mathrm{m}$.

In most of the conditions, calcium carbonate in calcite crystal type shows the spindle-shaped and cubic polymorph, while the vaterite type resembles the spherical shape. In the formation process of calcium carbonate, calcite is the stable crystal polymorph. Thus, the crystal grows into the prism shaped calcite without additives. Sphere is shaped since the ions have different effects in the electrolyte or the additives have large steric effect to deter the growth of calcium carbonate crystal. According to the dynamics of crystal growing, the nucleation rate of calcium carbonate is positive to the degree of supersaturation. Adding dissolvable salt can cause the salt effect to increase supersaturation degree of calcium carbonate. The critical dimension of particle nucleus and energy required in the nucleation process are decreased, while the nucleation rate increases. The rates of nucleation and growth are of competing relation, which means when the nucleation rate is high, the growth rate is low. On a macrolevel, the particle diameter decreases and, meanwhile, the gradient of concentration increases when the degree of supersaturation is high. Clustering or other polymorphs will be shaped since corners and edges of the crystal have larger areas than the center of the surface to take the accumulation of mass points. That is why in Figure 5 adding inorganic salt, alcohol, and organic acid salt, the particle diameter and polymorph of calcium carbonate will change significantly. In addition, the surfactant can change the surface state of the solution system and make the indissoluble particles disperse. In terms of Figure 5(e), the interaction of surfactant and $\mathrm{Ca}^{2+}$ helps the nucleation of vaterite in supersaturation solution and stops the growth and clustering of calcium carbonate particles. Thus, the diameter is shrunk.

\section{Conclusion}

In the solution of low degree of concentration with about $0.015 \mathrm{~mol} / \mathrm{L} \mathrm{Ca}^{2+}$ and under the condition of low degree of supersaturation, ammonification and carbonization methods are applied to make ultrafine particles of calcium carbonate. With low degree of supersaturation, the reaction rates of $\mathrm{Ca}^{2+}$ and $\mathrm{CO}_{3}{ }^{2-}$ are not that quick, so that it is expected to be easy to control the crystal polymorph. When the reaction system does not include ammonia, the precipitate of calcium carbonate is mainly of the crystal morphology of calcite and a little crystal morphology of vaterite. The proportion of calcite will be over $98 \%$. Adding ammonia to the solution helps to form the vaterite, and the precipitate of calcium carbonate is the mixture of calcite and vaterite. At the same time, a little aragonite is also formed. The influence of ammonia on crystal morphology of calcium carbonate precipitate is achieved by creating great partial degree of supersaturation. Ultrasound can also be applied to infer that ammonia can form calcium carbonate into spherical shape with steric effect. In addition, with forming the cubic or spindle-shaped crystal nucleus of calcium carbonate in the solution, ammonia can also function to concentrate partial $\mathrm{Ca}^{2+}$ and $\mathrm{CO}_{3}{ }^{2-}$ at the edge and corner direction and form the twin spherical calcium carbonate. Without other additives, the calcium carbonate formed is with a diameter of about 5-12 $\mu \mathrm{m}$. Inorganic salt, alcohol, or organic acid and salt can have significant effect on controlling the particle diameter of calcium carbonate and will trigger salt effect, which increases the degree of supersaturation of 


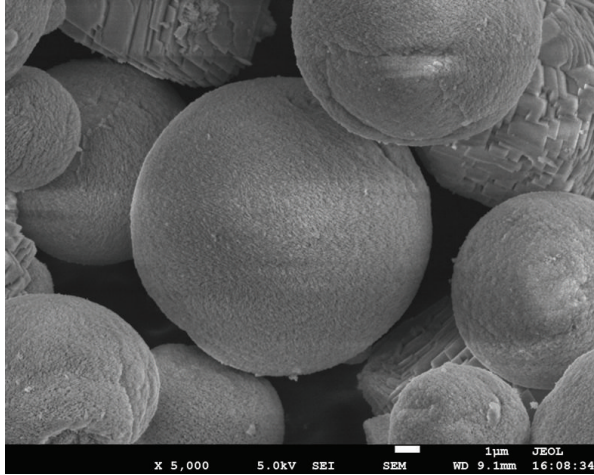

(a) Solutions: $\mathrm{NH}_{3}, 1.47 \mathrm{~mol} / \mathrm{L} ; \mathrm{CaSO}_{4}, 0.15 \mathrm{~mol} / \mathrm{L}$ $\mathrm{CO}_{2}$ gas: $55 \mathrm{~mL} / \mathrm{min} \times 20 \mathrm{~min}$

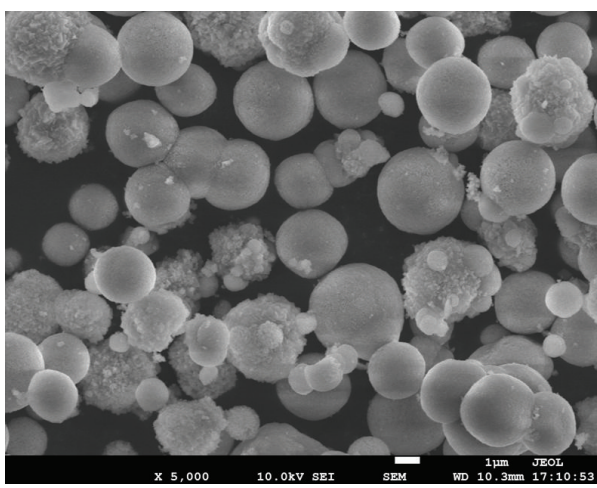

(c) Solutions: $\mathrm{NH}_{3}, 0.29 \mathrm{~mol} / \mathrm{L} ; \mathrm{CaSO}_{4}, 0.15 \mathrm{~mol} / \mathrm{L}$ $\mathrm{CH}_{3} \mathrm{CH}_{2} \mathrm{OH}, 1.72 \mathrm{~mol} / \mathrm{L} . \mathrm{CO}_{2}$ gas: $40 \mathrm{~mL} / \mathrm{min} \times$ $20 \mathrm{~min}$

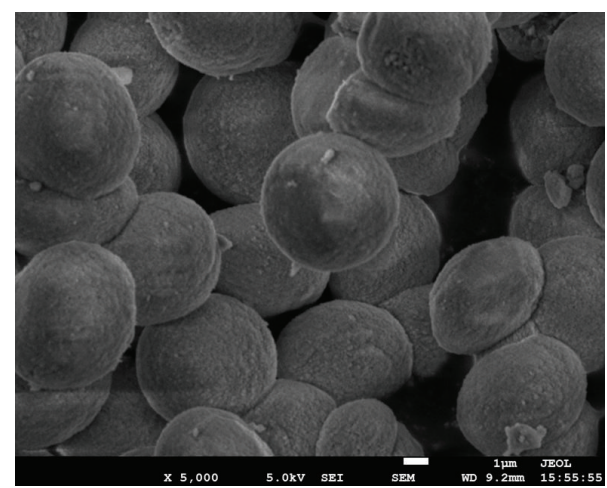

(b) Solutions: $\mathrm{NH}_{3}, 1.47 \mathrm{~mol} / \mathrm{L} ; \mathrm{CaSO}_{4}, 0.15 \mathrm{~mol} / \mathrm{L}$; $\mathrm{NaCl}, 1.65 \mathrm{~mol} / \mathrm{L}$. $\mathrm{CO}_{2}$ gas: $55 \mathrm{~mL} / \mathrm{min} \times 20 \mathrm{~min}$

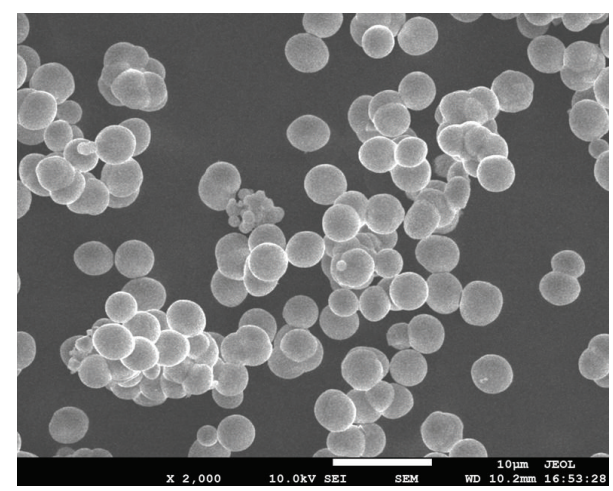

(d) Solutions: $\mathrm{NH}_{3}, 0.29 \mathrm{~mol} / \mathrm{L} ; \mathrm{CaSO}_{4}, 0.15 \mathrm{~mol} / \mathrm{L}$; $\mathrm{CH}_{3} \mathrm{COONa}, 1.21 \mathrm{~mol} / \mathrm{L} . \mathrm{CO}_{2}$ gas: $40 \mathrm{~mL} / \mathrm{min} \times$ $20 \mathrm{~min}$

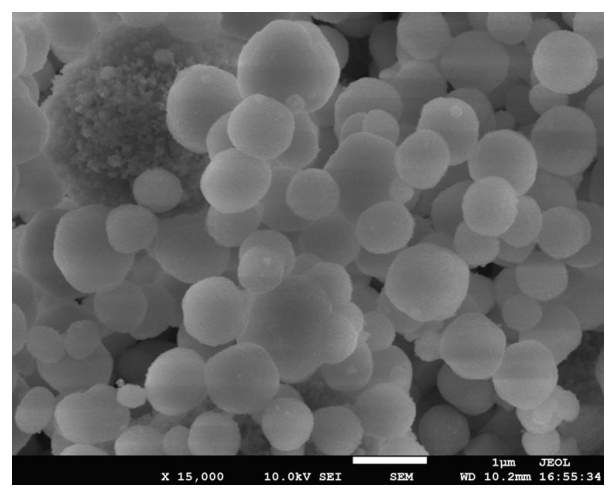

(e) Solutions: $\mathrm{NH}_{3}, 0.29 \mathrm{~mol} / \mathrm{L} ; \mathrm{CaSO}_{4}, 0.15 \mathrm{~mol} / \mathrm{L}$; anionic surfactant, $2 \mathrm{~mL} / \mathrm{L} . \mathrm{CO}_{2}$ gas: $40 \mathrm{~mL} / \mathrm{min} \times$ $20 \mathrm{~min}$

FIGURE 5: Morphology of calcium carbonate precipitate with different additives.

calcium carbonate and shrinks its size to about $3 \mu \mathrm{m}$. What is more, clustering occurs and the anionic surfactant can deter the clustering of calcium carbonate particles and shrink its size to $500 \mathrm{~nm} \sim 1 \mu \mathrm{m}$.

\section{Conflict of Interests}

The authors declare that they have no financial and personal relationships with other people or organizations that can inappropriately influence their works; there is no professional or other personal interest of any nature or kind in any product, service, and/or company that could be construed as influencing the position presented in, or the review of, the paper.

\section{Acknowledgments}

This work was financially supported by National Natural Science Foundation of China (51104097), the National Key Technology R\&D Program (2013BAC14B05), the Provincial 
Research Projects (2012021010-2, 20120313014-1), and the Program of International Science and Technology Cooperation (2012DFA91500).

\section{References}

[1] T. Sasaki, H. Mizuuchi, and K. Sakurai, "Chitosan derivatives/calcium carbonate composite capsules prepared by the layer-by-layer deposition method II stabilization of the shell by crosslinking," Journal of Nanomaterials, vol. 2011, Article ID 476752, 7 pages, 2011.

[2] C. Aniruddha and M. Satyendra, "Nano-Calcium carbonate $\left(\mathrm{CaCO}_{3}\right)$ /Polystyrene (PS) core-shell nanoparticle: it's effect on physical and mechanical properties of high impact polystyrene (HIPS)," Journal of Polymer Research, vol. 20, article 249, pp. $10-$ 1007, 2013.

[3] J. P. Paques, L. M. C. Sagis, C. J. M. van Rijn, and E. van der Linden, "Nanospheres of alginate prepared through w/o emulsification and internal gelation with nanoparticles of $\mathrm{CaCO}_{3}$," Food Hydrocolloids, vol. 40, pp. 182-188, 2014.

[4] V. Parakhonskiy Bogdan, M. Yashchenok Alexey, K. Manfred, and G. Skirtach Andre, "Colloidal micro- and nano-particles as templates for polyelectrolyte multilayer capsules," Advances in Colloid and Interface Science, vol. 207, pp. 253-264, 2014.

[5] A. Shafiu Kamba, M. Ismail, T. A. Tengku Ibrahim, and Z. A. B. Zakaria, "Synthesis and characterisation of calcium carbonate aragonite nanocrystals from cockle shell powder (Anadara granosa)," Journal of Nanomaterials, vol. 2013, Article ID 398357, 9 pages, 2013.

[6] W. Li, W.-S. Chen, P.-P. Zhou, L. Cao, and L.-J. Yu, "Influence of initial $\mathrm{pH}$ on the precipitation and crystal morphology of calcium carbonate induced by microbial carbonic anhydrase," Colloids and Surfaces B: Biointerfaces, vol. 102, pp. 281-287, 2013.

[7] S. P. Gopi and V. K. Subramanian, "Polymorphism in $\mathrm{CaCO}_{3}-$ effect of temperature under the influence of EDTA (di sodium salt)," Desalination, vol. 297, pp. 38-47, 2012.

[8] S. Kirboga and M. Öner, "Application of experimental design for the precipitation of calcium carbonate in the presence of biopolymer," Powder Technology, vol. 249, pp. 95-104, 2013.

[9] A. Verch, I. E. G. Morrison, R. V. D. Locht, and R. Kröger, "In situ electron microscopy studies of calcium carbonate precipitation from aqueous solution with and without organic additives," Journal of Structural Biology, vol. 183, no. 2, pp. 270277, 2013.

[10] S. Bai, G. Naren, M. Nakano, Y. Okaue, and T. Yokoyama, "Effect of polysilicic acid on the precipitation of calcium carbonate," Colloids and Surfaces A: Physicochemical and Engineering Aspects, vol. 445, pp. 54-58, 2014.

[11] B. Njegić-Džakula, G. Falini, L. Brečević, Ž. Skoko, and D. Kralj, "Effects of initial supersaturation on spontaneous precipitation of calcium carbonate in the presence of charged poly-1-amino acids," Journal of Colloid and Interface Science, vol. 343, no. 2, pp. 553-563, 2010.

[12] W. Li, L. Liu, W. Chen, L. Yu, W. Li, and H. Yu, "Calcium carbonate precipitation and crystal morphology induced by microbial carbonic anhydrase and other biological factors," Process Biochemistry, vol. 45, no. 6, pp. 1017-1021, 2010.

[13] M.-A. Popescu, R. Isopescu, C. Matei, G. Fagarasan, and V. Plesu, "Thermal decomposition of calcium carbonate polymorphs precipitated in the presence of ammonia and alkylamines," Advanced Powder Technology, vol. 25, pp. 500-507, 2014.
[14] Y. Liang, G. Chu, J. Wang et al., "Controllable preparation of nano- $\mathrm{CaCO}_{3}$ in a microporous tube-in-tube microchannel reactor," Chemical Engineering and Processing: Process Intensification, vol. 79, pp. 34-39, 2014.

[15] J.-H. Bang, Y. N. Jang, W. Kim et al., "Precipitation of calcium carbonate by carbon dioxide microbubbles," Chemical Engineering Journal, vol. 174, no. 1, pp. 413-420, 2011.

[16] K. Song, Y.-N. Jang, W. Kim et al., "Precipitation of calcium carbonate during direct aqueous carbonation of flue gas desulfurization gypsum," Chemical Engineering Journal, vol. 213, pp. 251-258, 2012.

[17] K. Song, Y. N. Jang, W. Kim, and et al, "Factors affecting the precipitation of pure calcium carbonate during the direct aqueous carbonation of flue gas desulfurization gypsum," Energy, vol. 65, pp. 527-532, 2014.

[18] W. Li, W.-S. Chen, P.-P. Zhou, S.-L. Zhu, and L.-J. Yu, "Influence of initial calcium ion concentration on the precipitation and crystal morphology of calcium carbonate induced by bacterial carbonic anhydrase," Chemical Engineering Journal, vol. 218, pp. 65-72, 2013.

[19] I. A. Bundeleva, L. S. Shirokova, O. S. Pokrovsky et al., "Experimental modeling of calcium carbonate precipitation by cyanobacterium Gloeocapsa sp.," Chemical Geology, vol. 374-375, pp. 44-60, 2014.

[20] Y. Sheng Han, G. Hadiko, M. Fuji, and M. Takahashi, "Crystallization and transformation of vaterite at controlled $\mathrm{pH}$," Journal of Crystal Growth, vol. 289, no. 1, pp. 269-274, 2006.

[21] A. Stoica-Guzun, M. Stroescu, S. Jinga, I. Jipa, T. Dobre, and L. Dobre, "Ultrasound influence upon calcium carbonate precipitation on bacterial cellulose membranes," Ultrasonics Sonochemistry, vol. 19, no. 4, pp. 909-915, 2012. 

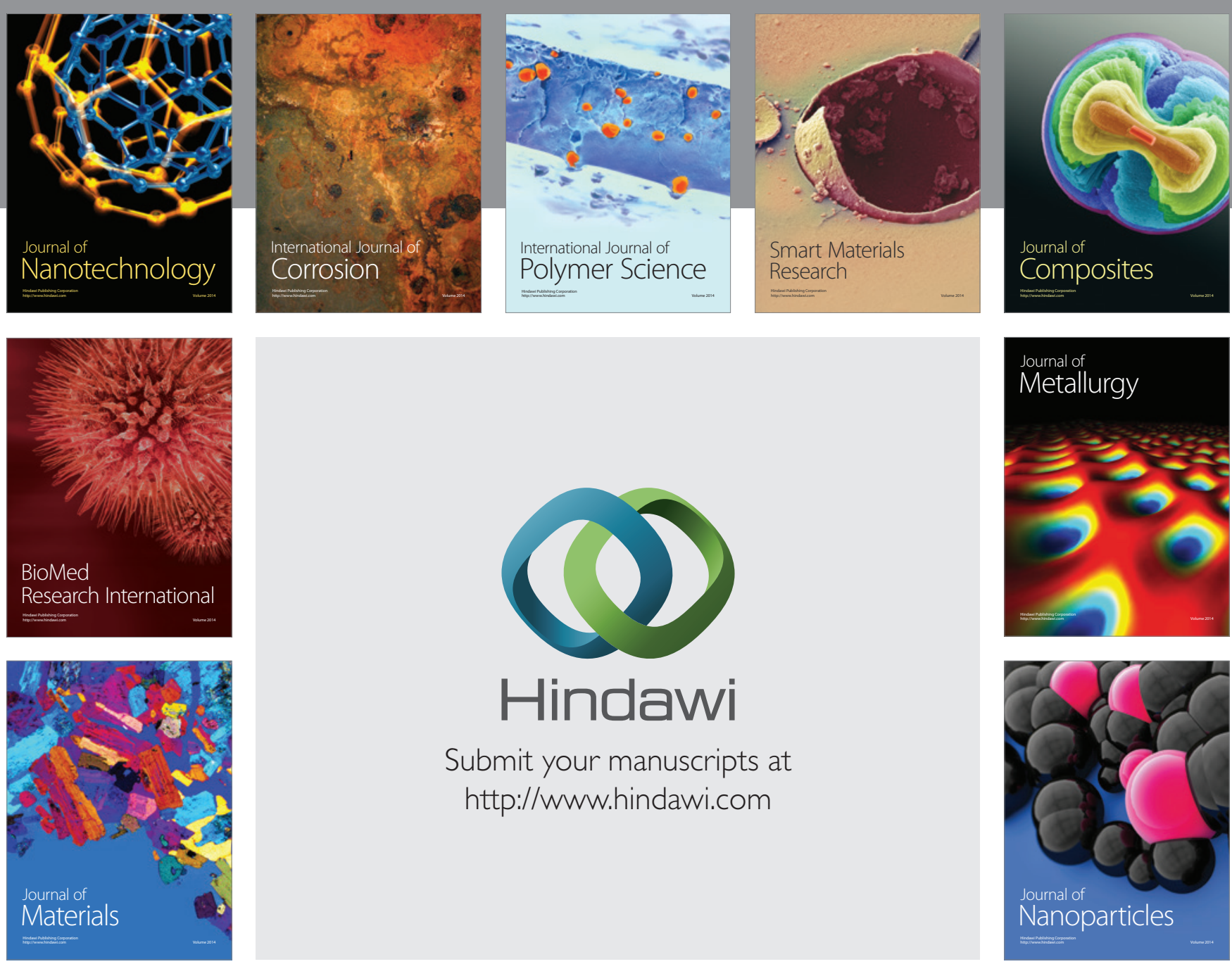

Submit your manuscripts at http://www.hindawi.com
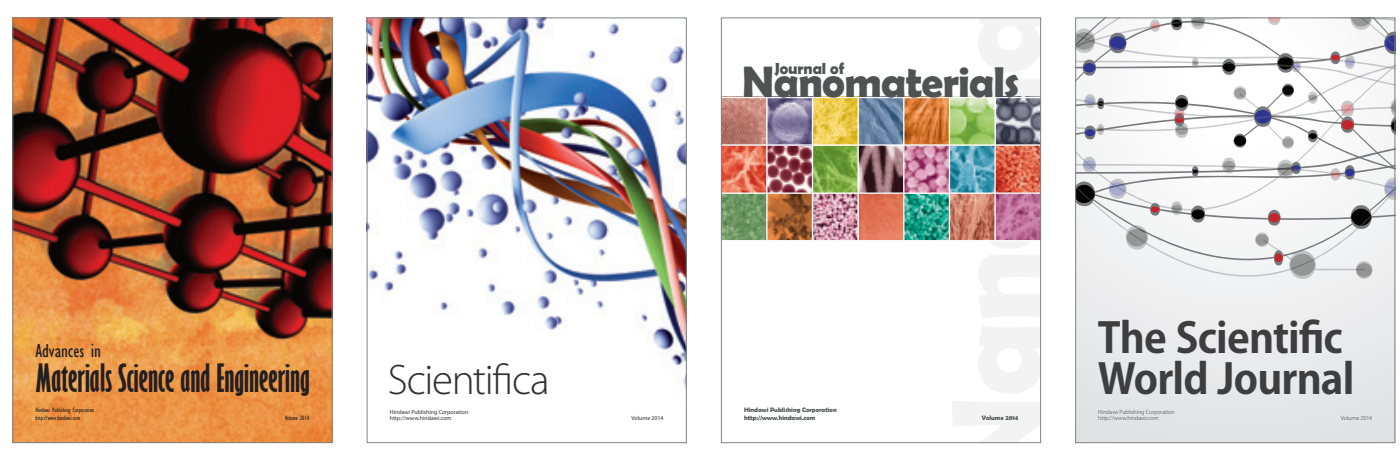

\section{The Scientific World Journal}
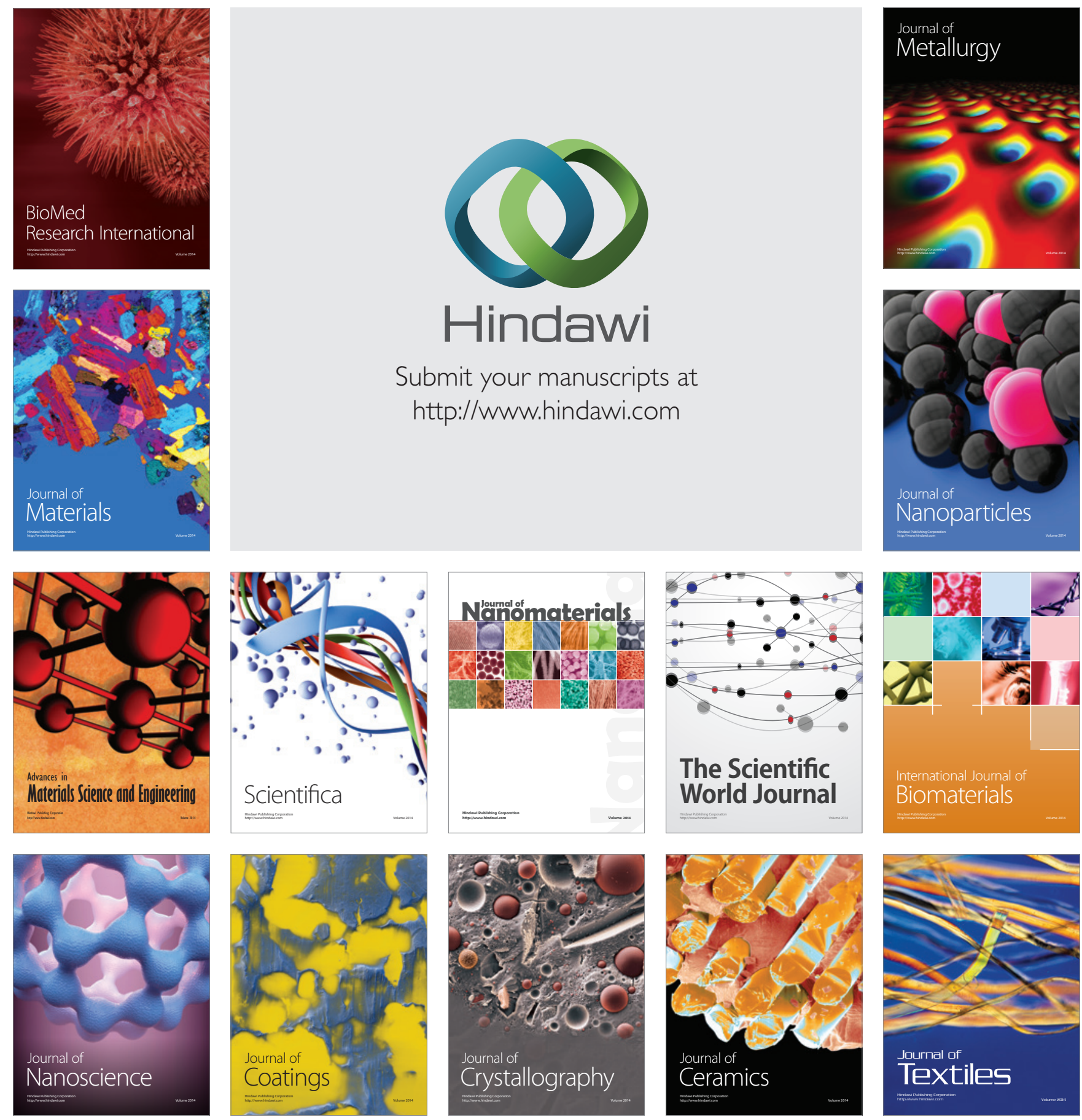